\title{
ESTIMATION OF CARDIAC SURGERY RESULTS
}

\section{ALEXEY LEONIDOVICH CHARYSHKIN, ALEXANDER NIKOLAEVICH YUDIN}

Department of Surgery, Ulyanovsk State University, 432970 Ulyanovsk, Russia. Email: charyshkin@yandex.ru

\author{
Received: 13 May 2017, Revised and Accepted: 12 October 2017
}

\section{ABSTRACT}

Objective: Estimation of cardiac surgery results after median sternal incision.

Methods: This work contains the results of surgical treatment of 220 patients who had cardiac surgeries performed by means of the median sternal incision at the State Healthcare Institution “Ulyanovsk Regional Clinical Hospital” during 2000-2014.

Results: The following surgical interferences were made: Coronary artery bypass grafting - 14 (6.3\%), mammary coronary bypass - 5 (2.3\%), combined coronary artery and mammary coronary bypass grafting - 81 (36.8\%), aortic valve replacement - 53 (24.1\%), mitral valve replacement $44(20 \%)$, atrial septal defect plasty - 7 (3.2\%), ventricular septal defect plasty - $3(1.4 \%)$, myxomas - 5 (2.3\%), and mediastinal neoplasms removal - $8(3.6 \%)$. The most frequent early complications after median sternal incision were wound pyoinflammatory complications that were observed in $32(14.5 \%)$ patients, pneumonia - defined in $17(7.7 \%)$ patients, mediastinitis - found in $5(2.3 \%)$ patients, sepsis - detected in $2(0.9 \%)$ patients, and acute cerebrovascular disease - observed in $1(0.5 \%)$ patient. The fatal outcome was observed in $2(0.9 \%)$ cases; the cause of death of the first $(0.5 \%)$ patient was multiple organ failure against the background of sepsis, and the cause of death of the second patient (0.5\%) was acute cerebrovascular disease.

Conclusion: The most frequent early post-operative complications the patients have after cardiac surgeries are wound pyoinflammatory complications (14.5\%), pneumonia (7.7\%), and mediastinitis (2.3\%).

Keywords: Median sternal incision, Post-operative complications, Cardiac surgery, X-ray.

(C) 2017 The Authors. Published by Innovare Academic Sciences Pvt Ltd. This is an open access article under the CC BY license (http://creativecommons. org/licenses/by/4. 0/) DOI: http://dx.doi.org/10.22159/ajpcr.2017.v10i12.19920

\section{INTRODUCTION}

In cardiovascular surgery, the most commonly used open-heart approach is the median sternal incision by means of which over 60 thousand surgeries are performed every year [1-5].

According to the literature dedicated to the studies of results of the open-heart approach use, there are a significant number of patients up to $6 \%$ - with pyoinflammatory complications in the post-operative period; the most severe complications are the mediastinitis and osteomyelitis of sternum and ribs [4-8].

The open sources provide data on the annual financial costs in one of the USA thoracic surgery hospitals' expenditures for the treatment of complications among patients after performing the surgical interferences by means of sternotomy, and these expenditures amount to half a million dollars [4,5,8-11].

The development and introduction of new methods of anesthesia and prevention of postmedian sternal incision inflammatory complications will improve the quality of treatment for patients with cardiovascular and respiratory diseases $[12,13]$. Everything listed above indicates the immediacy of this problem.

The object of this study is to estimate the cardiac surgery results after performing the median sternal incision.

\section{METHODS}

This work was carried out in accordance with the main directions of the scientific research program of the Federal State Budgetary Educational Institution of Higher Professional Education "Ulyanovsk State University" at the Department of Intermediate Level Surgery.
This work contains the results of surgical treatment of 220 patients who had cardiac surgeries performed by means of the median sternal incision at the State Healthcare Institution "Ulyanovsk Regional Clinical Hospital" during 2000-2014.

To support the set problem, we have used clinical laboratory, X-ray, and statistical methods of study.

To achieve the goals, we have used clinical laboratory, X-ray, ECG (Schiller Cardiovit AT-10 plus), EchoCG (General Electric Vivid E9), angiographic (Allura Clarity FD10 Philips), 24-h Holter ECG monitoring (cardiology equipment - 04-8 M), and statistical methods of study.

In laboratory studies, we determined the complete blood test, while the leukocytal intoxication index was calculated according to A.B. Reis formula.

All patients gave their informed voluntary consent to surgical interference and post-operative treatment.

The statistical processing of results was carried out using the Statistica 6 software package. When comparing the obtained parameters, we used the Student $t$-test for independent pair samples and $\chi^{2}$-test. The statistically significant differences were recognized as the differences with a confidence level of at least $95 \%$ with Bonferroni's correction for multiple comparisons.

\section{RESEARCH FINDINGS}

A total of 220 patients were operated by means of median sternal incision (Table 1); among them, with CHD II, III, IV FR - 100 (45.5\%), 
aortal valvular disease - 53 (24.1\%), mitral valvular disease - 44 (20\%), atrial septal defect $-7(3.2 \%)$, ventricular septal defect $-3(1.4 \%)$, myxomas - 5 (2.3\%), and mediastinal neoplasms - 8 (3.6\%) of patients.

The most frequent intercurrent diseases were chronic gastritis - 35.4\% of patients, obesity of the $1^{\text {st }}$ degree $-27.8 \%$, and diabetes mellitus $21.5 \%$.

The following surgical interferences were performed (Table 2): Coronary artery bypass grafting - 14 (6.3\%), mammary coronary bypass $-5(2.3 \%)$, coronary artery and mammary coronary bypass grafting - $81(36.8 \%)$, aortic valve replacement - $53(24.1 \%)$, mitral valve replacement - $44(20 \%)$, atrial septal defect plasty - $7(3.2 \%)$, ventricular septal defect plasty - $3(1.4 \%)$, myxomas $-5(2.3 \%)$, and mediastinal neoplasms removal - 8 (3.6\%).

The most frequent early complications after median sternal incision were wound pyoinflammatory complications that were observed in 32 $(14.5 \%)$ patients, pneumonia - in $17(7.7 \%)$ patients, mediastinitis - in 5 $(2.3 \%)$ patients, sepsis - in $2(0.9 \%)$ patients, and acute cerebrovascular disease - in $1(0.5 \%)$ patient (Table 3, Fig. 1).

The fatal outcome was observed in $2(0.9 \%)$ cases; the cause of death of the first $(0.5 \%)$ patient is multiple organ failure against the background of sepsis, and the case of death of the second patient $(0.5 \%)$ is acute cerebrovascular disease.

Table 1: Diseases of studied patients

\begin{tabular}{ll}
\hline Diagnosis & Number of patients (\%) \\
\hline CHD. Stenocardia II fibrous ring & $5(2.3)$ \\
CHD. Stenocardia III fibrous ring & $64(29)$ \\
CHD. Stenocardia IV fibrous ring & $31(14.1)$ \\
Aortal valvular disease & $53(24.1)$ \\
Mitral valvular disease & $44(20)$ \\
Atrial septal defect & $7(3.2)$ \\
Ventricular septal defect & $3(1.4)$ \\
Myxomas & $5(2.3)$ \\
Mediastinal neoplasms & $8(3.6)$ \\
Total & $220(100)$ \\
\hline
\end{tabular}

Table 2: Characteristics of surgical interferences performed by means of median sternal incision

\begin{tabular}{ll}
\hline Surgical interference & $\begin{array}{l}\text { Number of } \\
\text { patients (\%) }\end{array}$ \\
\hline Coronary artery bypass grafting & $14(6.3)$ \\
Mammary coronary bypass & $5(2.3)$ \\
Coronary artery and mammary coronary bypass & $81(36.8)$ \\
grafting & \\
Aortic valve replacement & $53(24.1)$ \\
Mitral valve replacement & $44(20)$ \\
Atrial septal defect plasty & $7(3.2)$ \\
Ventricular septal defect plasty & $3(1.4)$ \\
Myxomas & $5(2.3)$ \\
Mediastinal neoplasms removal & $8(3.6)$ \\
Total & $220(100)$ \\
\hline
\end{tabular}

Table 3: Early post-operative complications

\begin{tabular}{ll}
\hline Early post-operative complications & Number of patients (\%) \\
\hline Wound pyoinflammatory complications & $32(14.5)$ \\
Mediastinitis & $5(2.3)$ \\
Pneumonia & $17(7.7)$ \\
Sepsis & $2(0.9)$ \\
Acute cerebrovascular disease & $1(0.6)$ \\
Total & $57(25.9)$ \\
\hline
\end{tabular}

\section{Clinical examples}

Patient

A.A., 60-year-old, received medical treatment in cardiac surgery department from January 08, 2013 to March 20, 2013.

The patient was admitted to the department with complaints of labored breathing when accelerating the walking pace and coming upstairs to the $2^{\text {nd }}$ floor. Cardiac function failure, heartbeat with irregular Rhythm were diagnosed. Occasional lower limbs edema and blood pressure rise up to $220 / 100 \mathrm{mmHg}$.

During the final D-echocardiographic coronary vessel study made on January 08,2013 , the mitral valve looked the following way: Mitral annulus $-41 \mathrm{~mm}$, mitral slit-shaped opening, significant stenosis of mitral annulus, mitral opening size according to gradient half-time

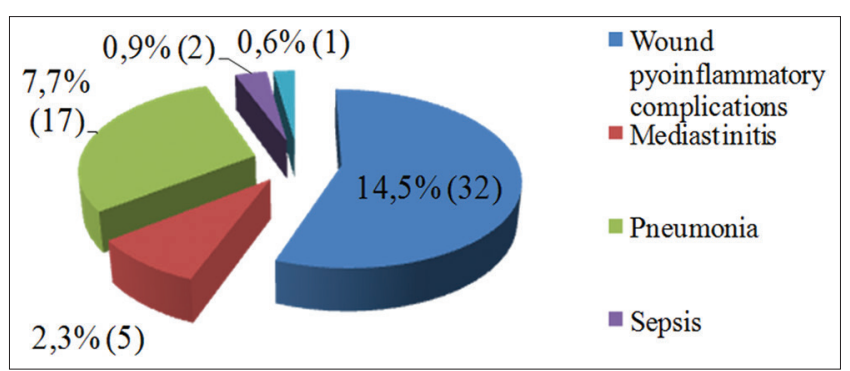

Fig. 1: Early post-operative complications of patients after sternotomy

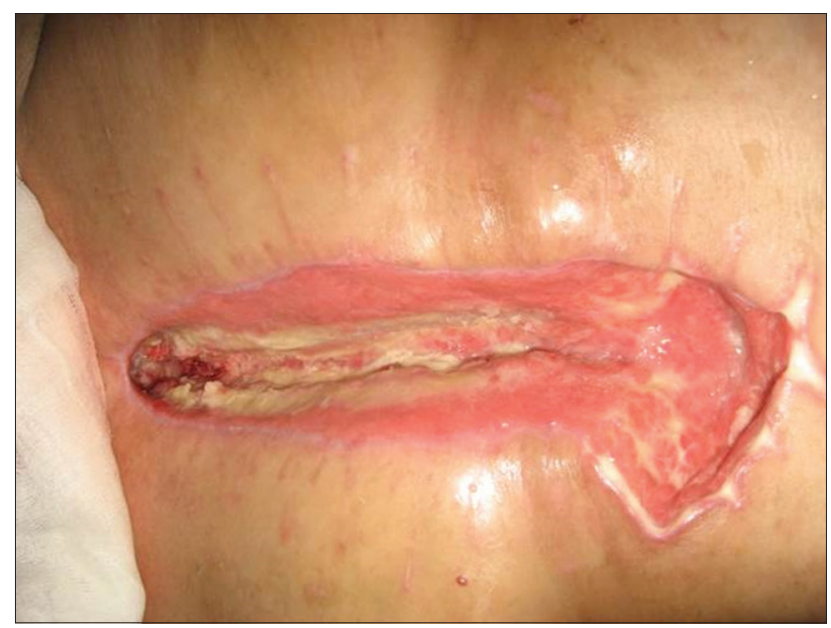

Fig. 2: Patient A.A. Lack of sternum sutures. Sternum osteomyelitis. Long-term nonhealing poststernal wound

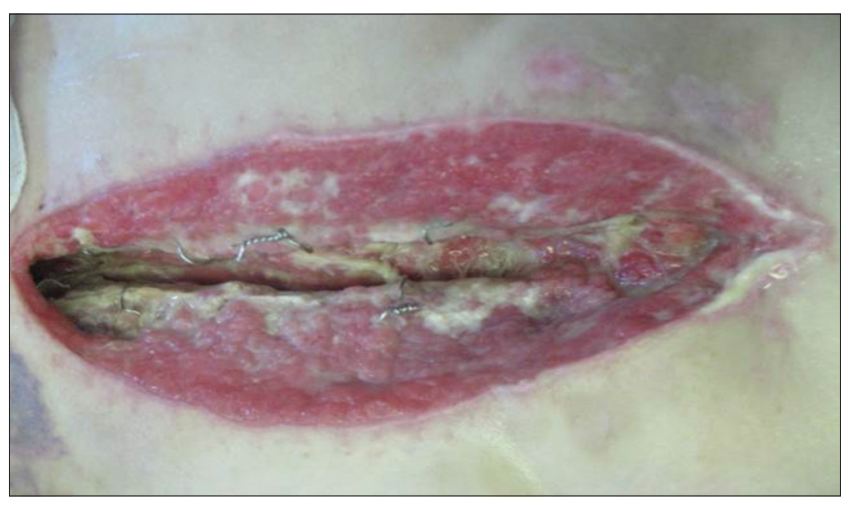

Fig. 3: Patient P.A. Lack of sternum sutures. Long-term nonhealing poststernal wound 
decay $-1.1 \mathrm{~cm}^{2}$, maximum gradient on mitral annulus $-14.0 \mathrm{mmHg}$, and planimetrically $1.0 \mathrm{~cm}^{2}$. The $1^{\text {st }}$ degree MP. TV, $P V$, and AV are unchanged. FC TV(33 mm) is not expanded. The $1^{\text {st }}$ is diagnosed. The average pressure in PV is $24.6 \mathrm{mmHg}$ - incomplete pulmonary hypertension. The systolic pressure in PV at TV is $37.0 \mathrm{mmHg}$. The left auricle is 50 $\mathrm{mm} \times 58 \mathrm{~mm} \times 53 \mathrm{~mm}$ in size; incomplete dilatation. Left ventricle morphometry: EDD - $51 \mathrm{~mm}$, ESD - $34 \mathrm{~mm}$, EDV - $125 \mathrm{ml}$, ESV - $47 \mathrm{ml}$, $\mathrm{SV}-77 \mathrm{ml}, \mathrm{EF}-62 \%$, and FS $-34 \%$. Myocardial contractility is normal.

\section{Clinical diagnosis}

Clinical diagnosis is the following:

- Chronic rheumatic heart disease;

- Severe mitral valve stenosis, mitral valve calcification 1 degree;

- Dilation of atrium;

- Relative incompetence of tricuspid valve of the $2^{\text {st }}$ degree;

- Constant form of atrium fibrillation;

- Cardioembolic syndrome - thrombosis of left lower leg arteries dated 08/2012;

- Arterial hypertension of the $2^{\text {nd }}$ degree, risk 3 . CHF $-2 \mathrm{~A}, 3 \mathrm{FC}$.

Post-operative condition: Mitral valve prosthetics with a mechanical prosthesis "MedInzh-2" No.29, annuloplasty of tricuspid valve by DeVega, and ligation of LA appendage under conditions of artificial blood circulation dated January 10, 2013. Reosteosynthesis of sternum dated February 11, 2013.

\section{Long-term nonhealing post-operative wound}

Hospital-acquired bilateral pneumonia (February 15, 2013).

Diagnosis is the following:

- Left lower-limbs varicose vein disease;

- Choledocholithiasis;

- Calculous cholecystitis.

Surgery dated January 10, 2013: Median sternal incision

- Prosthetic appliance was made for mitral valve with a mechanical prosthesis "MedInzh-2" No.29;

- annuloplasty of tricuspid valve by De-Vega;

- ligation of LA appendage under conditions of artificial blood circulation and pharmacological hypothermic cardioplegia.

The post-operative period was complicated by the long-term nonhealing poststernal wound, lack of sternum sutures with the phenomena of sternum osteomyelitis, and divergence of edges (Fig. 2). Twice a day on the everyday basis the dressings with Betadine, hypertonic solution, and "Levomekol" puncture were made; additional lytic enzymes were applied onto the wound. The patient had significant pains in the poststernal wound during the entire post-operative period up to the sternal reclosure surgery which required additional daily pain treatment by intramuscular injection of nonnarcotic analgesics.

\section{Surgery dated February 11, 2013: Sternal reclosure. Resuturing.}

After the removal of secondary sutures, the divergence of edges at a distance of about $2 \mathrm{~cm}$ was observed in the middle third of the wound.

At the time of the discharge on March 20,2013, a slight defect of $2 \mathrm{~cm} \times 2 \mathrm{~cm}$ in size and $1 \mathrm{~cm}$ in depth preserved in the middle third of the wound. The bottom and the walls of the wound were formed by a granulated tissue; dressings were made with "Levomekol" puncture implementation. Further treatment was recommended in the surgeon office at the place of residence.

The duration of in-hospital post-operative period was 69 days.

\section{Patient}

P.A., 45-year-old, received medical treatment at the cardiac surgery department from April 19, 2013 to May 27, 2013.

The patient was admitted to the department with complaints of labored breathing during minimal physical exercises increasing in horizontal position; cough with a small amount of mucous expectorations; praecordium severity and cardiac function failure.

During the final D-echocardiographic coronary vessel study made on April 19, 2013, the mitral valve looked the following way: Mitral annulus - $41 \mathrm{~mm}$; posterior mitral leaflet had free-floating distal segment; prolapses in the body area were over $9 \mathrm{~mm}$; leaflets were a little bit thickened; and MP eccentric velocity turbulent along the AMVL $4^{\text {th }}$ degree. TV and PV were unchanged. FC TV was $29 \mathrm{~mm}$.

Pulmonary heart parameters are the following:

- Prostate is $20 \mathrm{~mm}$;

- RA is $46441 \mathrm{~mm}$;

- $\mathrm{PV}$ artery is $32 \mathrm{~mm}$.

The systolic pressure under tricuspid regurgitation in PV was 70.0 $\mathrm{mmHg}$. Ascending aorta was $31 \mathrm{~mm}, \mathrm{AV}$ was $17 \mathrm{~mm}$. Maximum gradient in $\mathrm{mmHg}$ was the following:

- Trans-aortic was 5.2,

- $\quad$ speed was $1.1 . \mathrm{m} / \mathrm{s}$.

- Left auricle was $47 \mathrm{~mm}$

Left ventricle parameters were:

- EDD was $66 \mathrm{~mm}$;

- ESD was $40 \mathrm{~mm}$

- $\quad$ EDV was $226 \mathrm{ml}$;

- $\quad$ ESV was $71 \mathrm{ml}$;

- SV was $155 \mathrm{ml}$

- EF was 69\%, and FS was 39\%;

- Interventricular septum in diastole was $8.0 \mathrm{~mm}$.

- left ventricular posterior wall in diastole was $9.0 \mathrm{~mm}$.

Myocardial contractility was normal. Diastolic function was intact. Pericardium was unchanged. Regional contractility was intact.

\section{Clinical diagnosis}

- Post-traumatic rupture of mitral valve chordae tendineae

- Mitral valve insufficiency was of 4 degree;

- Dilation of left ventricle auricle;

- High pulmonary hypertension;

- Relative incompetence of tricuspid valve of 2-3rd th degrees;

- Arterial hypertension of the 2 nd degree;

- CHF - 2-A

- $-4 \mathrm{FC}$

Postoperative condition: Mitral valve prosthetics with a mechanical prosthesis "MedInzh-2" No.29, annuloplasty of tricuspid valve by De-Vega under the conditions of artificial blood circulation, and pharmacological hypothermic cardioplegia dated April 24, 2013. Hemodynamically, significant paroxysms of auricular flutters of the $1^{\text {st }}$ type in the post-operative period; restoration of sinus rhythm of LA electrophysiological study (May 06, 2013). Long-term nonhealing post-operative wound.

Surgery dated April 24, 2013: Median sternal incision. Mitral valve prostheticswithamechanicalprosthesis“"MedInzh-2"No.29, annuloplasty of tricuspid valve by De-Vega under the conditions of artificial blood circulation, and pharmacological hypothermic cardioplegia.

The post-operative period was complicated by the long-term nonhealing poststernal wound and lack of sternum sutures with divergence of edges (Fig. 3). Twice a day on the everyday basis the dressings with Betadine, hypertonic solution, and "Levomekol" puncture were made; additional lytic enzymes were applied onto the wound. The patient had significant pains in the poststernal wound during the entire post-operative period up to the sternal reclosure surgery which required additional daily pain treatment by intramuscular injection of nonnarcotic analgesics.

Surgery dated February 11, 2013: Sternal reclosure. Resuturing. 
On May 27, 2013, the patient was discharged in satisfactory condition for the further care of cardiologist at the place of residence.

The duration of in-hospital post-operative period was 33 days.

\section{DISCUSSION}

Literary sources indicate that after sternotomy and cardiac surgeries the mediastinitis occurs during the post-operative period in $3 \%$ of cases; the pyoinflammatory complications are observed in $20 \%$ of patients [4-5,8-11]. The risk factors for the development of pyoinflammatory complications are repeated surgeries, females, obesity, diabetes mellitus, multifocal atherosclerosis, coronary artery bypass grafting, infective endocarditis, post-operative pneumonia, and urinary tract infections.

Thus, our study and data from literature sources [4-5,8-11] show that the increase of post-operative complications, the severity of pain syndrome, prolongation of hospitalization, and rehabilitation period occur in patients after extensive thoracotomy.

Taking into account everything listed above, it could be concluded that an important task of modern thoracic surgery is optimization of surgical techniques and prevention of pyoinflammatory complications in patients after extensive thoracotomy.

\section{CONCLUSION}

The most frequent early post-operative complications the patients have after cardiac surgeries are wound pyoinflammatory complications (14.5\%), pneumonia (7.7\%), and mediastinitis (2.3\%).

This study was made with the financial support of the Ministry of Education and Science of the Russian Federation as a part of the state support of the scientific project No.18.7236.2017/BCh

\section{REFERENCES}

1. Bokeria LA, Stupakov IN, Gudkova RG. The features of cardiovascular and X-ray endovascular surgery statistics in the Russian federation. Zdravookhr 2013;5:22-32.

2. Shenoy R, Bhat R, Srinivasan M, Mahabala C, Bhaskaran U. Correlation between insulin resistance and severity of coronary artery disease in non-diabetes. Asian J Pharm Clin Res 2016;9:331-3.

3. Charyshkin AL, Yakovlev SA, Bekin VY. Preperitoneal Blockade among Patients after Laparotomy. Vest Eksp I Klinkhir 2011;4:354-55.

4. Charyshkin AL, Vanina NV, Lebedeva LM, Charyshkina YU. Technique for tracheostomy closure. Life Sci J 2013;10:344-7.

5. Charyshkin AL, Yudin AN. The results of treatment of patients after median sternotomy. Life Sci J 2014;11:342-5.

6. Bouchot O, Guenancia C, Kahli A. Reoperative off-pump coronary artery bypass grafting: Analysis of early and late outcome. Interact Cardiovasc Thorac Surg 2007;5:45

7. Breivik H, Borchgrevink PC, Allen SM, Rosseland LA, Romundstad L, Hals EK, et al. Assessment of pain. Br J Anaesth 2008;101:17-24.

8. Francel TJ, Kouchoukos NT. A rational approach to wound difficulties after sternotomy: The problem. Ann Thorac Surg 2001;72:1411-8.

9. Pechetov AA. Methods of Joining the Sternum with Various Materials after the Median Sternotomy. Diss., Moscow; 2010.

10. Johnson C. Visual analog scale versus numeric pain scale: What is the difference? J Chiropr Med 2005;4:43-4.

11. Al-Ruzzeh S, Athanasiou T, Mangoush O, Wray J, Modine T, George S, et al. Predictors of poor midterm health related quality of life after primary isolated coronary artery bypass grafting surgery. Heart 2005;91:1557-62.

12. Sahoo B. Vecuronium and cardiac arrest. Int J Pharm Pharm Sci 2016;8:342-3

13. Rajendra N, RajA, Madhusudhana R, Das P, Krishnamurthy D. Anaesthetic management of a patient with previous lobectomy posted for emergency modified radical mastoidectomy. Int J Pharm Pharm Sci 2016;8:305-6. 